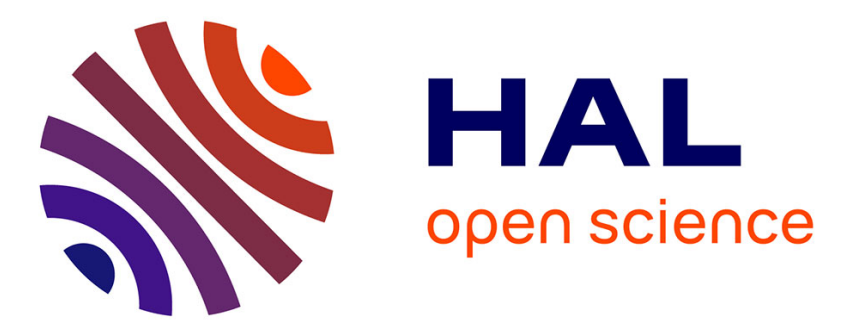

\title{
The Potential of Shape Memory Alloys in Deployable Systems - A Design and Experimental Approach
}

Philippe Hannequart, Michaël Peigney, Jean-François Caron, Olivier Baverel, Emmanuel Viglino

\section{To cite this version:}

Philippe Hannequart, Michaël Peigney, Jean-François Caron, Olivier Baverel, Emmanuel Viglino. The Potential of Shape Memory Alloys in Deployable Systems - A Design and Experimental Approach. Humanizing Digital Reality, Springer, pp.237-246, 2017, 978-981-10-6610-8. 10.1007/978-981-10-66115_21. hal-01591902

\section{HAL Id: hal-01591902 \\ https://hal-enpc.archives-ouvertes.fr/hal-01591902}

Submitted on 22 Sep 2017

HAL is a multi-disciplinary open access archive for the deposit and dissemination of scientific research documents, whether they are published or not. The documents may come from teaching and research institutions in France or abroad, or from public or private research centers.
L'archive ouverte pluridisciplinaire HAL, est destinée au dépôt et à la diffusion de documents scientifiques de niveau recherche, publiés ou non, émanant des établissements d'enseignement et de recherche français ou étrangers, des laboratoires publics ou privés. 


\title{
The Potential of Shape Memory Alloys in Deployable Systems - a Design and Experimental Approach
}

\author{
Philippe Hannequart ${ }^{1,2}$, Michael Peigney ${ }^{1}$, Jean-François Caron ${ }^{1}$, Olivier Baverel ${ }^{1}$ and \\ Emmanuel Viglino ${ }^{2}$ \\ ${ }^{1}$ Université Paris-Est, Laboratoire Navier (UMR 8205), CNRS, Ecole des Ponts ParisTech, \\ IFSTTAR, 77455 Marne la vallée, France \\ 2 Arcora, Groupe Ingérop, Rueil-Malmaison, France \\ philippe.hannequart@enpc.fr
}

\begin{abstract}
This study focuses on deployable systems actuated by shape memory alloys in the perspective of designing adaptive sun shading devices for building facades. We first set the context of smart materials for adaptive facades and underline the remarkable characteristics of shape memory alloys for mechanical actuation purposes. After outlining the constraints on the integration of this material into deployable structures, we introduce three different prototypes actuated by shape memory alloy wires. They have been fabricated and tests have been carried out on two of them. Finally, we present some perspectives on the use of these actuators for solar shading systems in façade engineering.
\end{abstract}

Keywords: Shape memory alloys, Actuator, Adaptive structures, Deployable structures.

\section{Introduction}

The building envelope presents an increasing amount of mechanical devices: the building can thus adapt to changing operating conditions and meet strong technical requirements, including energy consumption specifications. However, common mechanical systems like electrical motors and rigid-link mechanisms are not fully satisfying in architecture [3]. A whole range of new materials has been researched in the last years: the so-called "smart materials" are able to react to external stimuli and produce an output that can be exploited by engineers and designers. They can convert one form of energy (mechanical, thermal, electric, magnetic, chemical, etc...) into another [7]. In particular, those materials could lead to new kinetic elements in facades which must adapt to climatic changes. We focus on deployable solar shading systems: the large glass facades in office buildings require an efficient sun protection. But current products only offer limited geometrical freedom, and shape-changing materials could foster the emergence of new architectural components. Shape memory alloys (SMA) present some remarkable properties and are being investigated through the design and analysis of prototypes resorting to different actuation principles. 


\section{Shape Memory Alloys}

Morphing smart materials include SMA, shape memory polymers [1], bimetals and piezoelectric materials. Standing out among these materials, SMA can undergo large deformations (up to $8 \%$ ) and return to their original shape with a high recovery force when heated, which is known as the "shape-memory effect". This feature relies on a solidsolid phase change at the crystal lattice level (from austenite to martensite and conversely) resulting in a coupling between temperature and mechanical loads. SMA are widely used as actuators or shape-changing devices in microelectronics, biomedicine and aerospace applications [5]. Nickel-Titanium is the most widespread alloy because of its satisfying fatigue properties and exceptional actuation qualities. However, SMA have not been used at a large scale in architecture yet, in spite of some remarkable features like their silent actuation, an ultra-low weight, the ability to both sense and actuate, and the freedom of shape they allow.

One main characteristic of SMA actuators is their small stroke and high output force: in order to develop kinetic shading devices, an amplification of that small stroke is needed. Hysteresis is another characteristic of the thermomechanical response of SMA, and it has consequences on the behavior of SMA-based actuators. Either upon mechanical loading or upon thermal loading, the behavior of SMA is not the same during loading and during unloading. This hysteresis is related to the solid-solid phase change happening in SMA. The consequence for SMA actuators is that the position of the structure cannot be determined only by knowing the current wire temperature: it also depends on the loading history.

\section{Integration into Morphing Structures}

SMA can be manufactured in various shapes (wires, sheets, tubes, etc...). Due to their high cost and significant environmental footprint, the use of those alloys can only be considered for a small actuating part of a façade element, transmitting efforts to a larger structure made of cheaper materials. Because of this need to minimize the SMA quantity, and because the simulation of its complex three-dimensional thermomechanical behavior is numerically challenging, we chose to focus on SMA traction wires and their one-dimensional behavior. In this case, the SMA wires need to be pre-strained in order to undergo the shape-memory effect upon heating: the wire will try to recover its initial, unstrained shape, or, if kinematically constrained, will generate high stresses which can be used for actuation. A computationally efficient, thermomechanical SMA model has been developed in a parallel research [4] and can be exploited to analyse the response of SMA actuators: the algorithm's one-dimensional simplification enables to simulate systems including SMA wires, which can also be embedded into a host material or fixed to a host structure. A User-Material subroutine (UMAT) has been implemented for the finite-element code ABAQUS.

For shading applications, changes of temperature due to addition of ambient temperature and absorption of the material under solar radiation could heat the Nickel-Titanium wires, resulting in a truly passive device, but an electrical heating by Joule effect 
has been chosen for a better control of the device. SMA wires actuated by shapememory effect must initially find themselves in a pre-strained state. For this reason, such devices actuated by shape-memory effect need an external spring-back force in order to return to their pre-strained shape after actuation.

Various kinematic amplification strategies can be identified in engineering [2], in particular the eccentricity of the actuator, the bilayer effect, controlled buckling, and torsion-induced movements. They were adapted to the use of SMA as an actuator. Different prototypes of shape morphing devices for architecture could be designed and fabricated.

\section{$4 \quad$ Prototyping}

\subsection{A Bilayer-type Actuator}

The first prototyped actuator exploits the bilayer effect: two thin materials are kinematically constrained together, and both materials have different thermal behaviors. A change of temperature results in different strains in both materials, which bring the whole structure to bend. In our case, the first material is a $1 \mathrm{~mm}$ thick wooden lamella, whose reaction to a temperature change is negligible. The second material is a $0.5 \mathrm{~mm}$ diameter pre-strained SMA wire provided by Ingpuls $\mathrm{GmbH}$, which shortens upon heating. They have been fixed with a humidity-cured ethyl-based instant adhesive (Loctite). When the heated wire contracts due to the shape-memory effect, the wood-SMA lamella bends, and upon cooling it return to its original state (the springback force is the elastic strain energy contained in the wooden lamella). Notice that in the non-actuated state, the structure is still bent, because of the wire pre-strain, as seen in Fig. 1. This prototype is similar to the adaptive SMA-composite beam presented in [8]. 


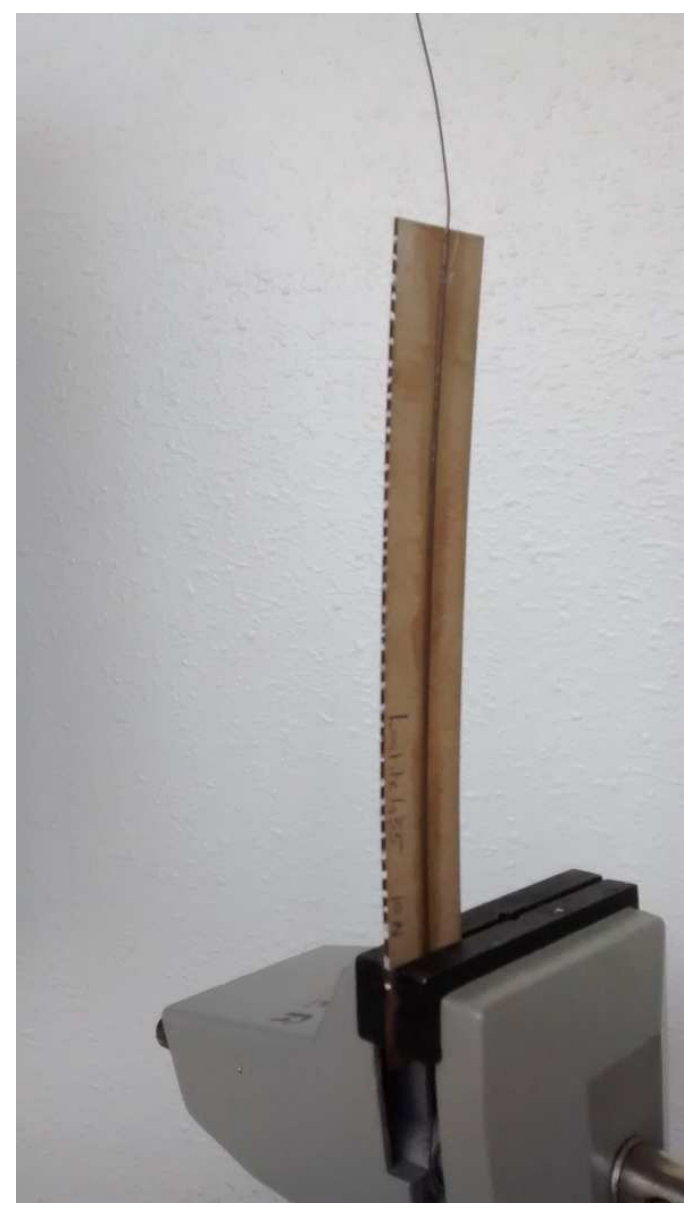

Fig. 1. Bilayer-type actuator composed of a wooden lamella and an SMA wire: initial state at ambient temperature

Actuation tests were carried out on this prototype, the SMA wire, initially at ambient temperature, being actuated by resistive heating (Joule effect). The wire temperature was measured by a thermocouple fixed on the wire with a highly thermally conductive silicon paste. Indeed, the resistivities of the martensitic and austenitic phase are different: the wire temperature cannot be inferred from the electrical input power. The radius of curvature of the lamella has been measured by digital image correlation (DIC) with the commercial software GOM Correlate (Fig. 2). It can be observed that the curvature is homogeneous along the lamella. Indeed, locally the SMA wire can be modelled as an excentric force acting on the lamella. Considering the lamella as a beam, uniform stresses in the wire lead to a uniform bending of the lamella. 


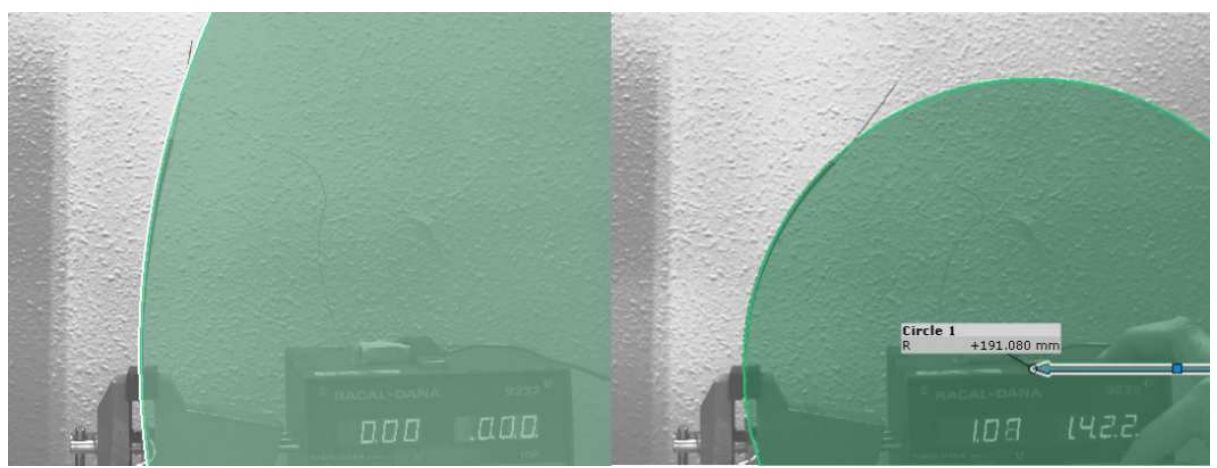

Fig. 2. Curvature measurements for the bilayer-type actuator: initial state at ambient temperature (left), actuated state with resistive heating (right)

The presented test has been carried out after approximately 10 previous actuation cycles. Two consecutive tests gave similar measurements, and we can thus suppose that the system's behavior is stabilised. The curvature of the lamella has then been plotted with respect to the wire temperature in Fig. 3. The measurements highlight the actuator's hysteresis described in Sect. 1: there is a strong difference between the heating and the cooling curve. The cooling curve does not completely reach the initial state, maybe because of some residual strains in the wooden lamella, and probably because the test was interrupted too early. We can identify a stable "hot" state: at temperatures higher than $58^{\circ} \mathrm{C}$, the prototype always presents the same curvature. In the same way, if the difference between ambient temperature and actuation temperature were higher we could identify a "cold" state, with no geometrical variations below a certain temperature. Between those two temperatures, the hysteresis prevents from being able to determine the curvature at a given temperature: the loading history has to be known. This hysteresis is a material property which is related to the dissipative nature of the phase change, it does not vary with cycling and has to be considered in any design with SMA. 


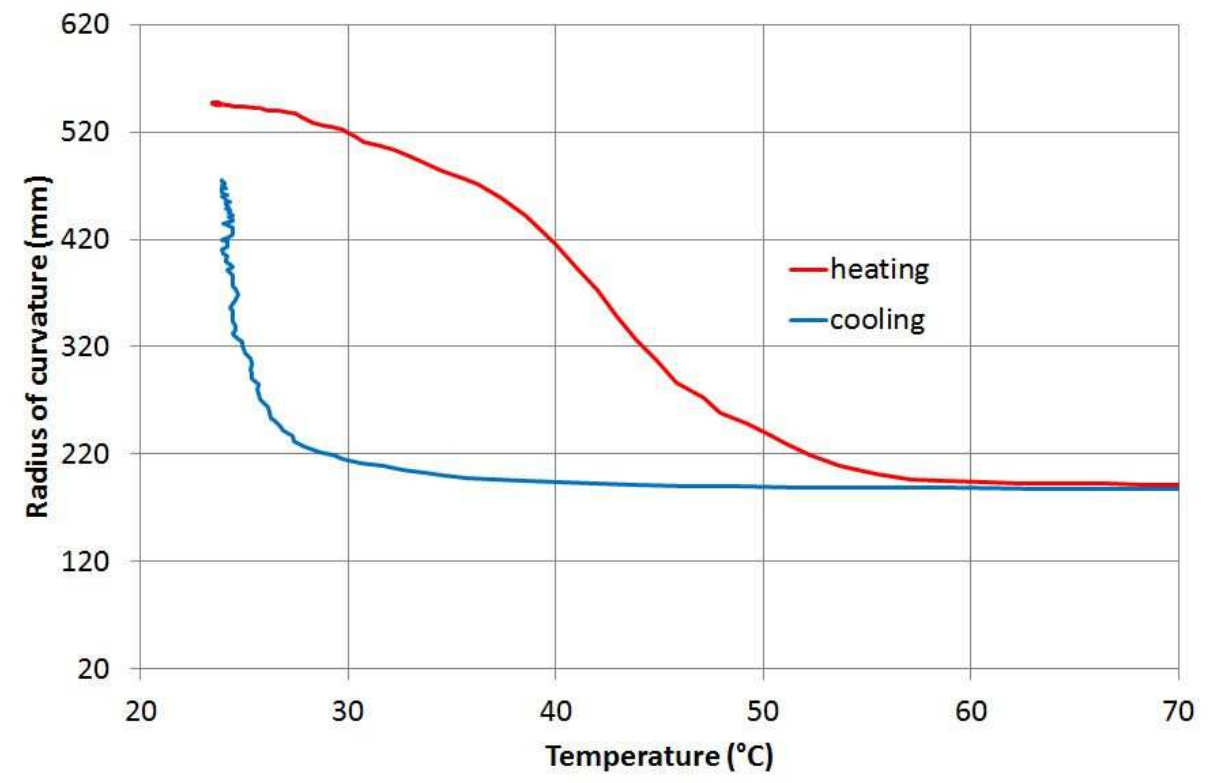

Fig. 3. Actuation test: Measurements of the actuator's radius of curvature with respect to the wire temperature - Heating curve and cooling curve

This way of embedding or fixing SMA into/onto a two-dimensional host material (ribbon, thin shell) is very promising in architecture: whereas the actuator and the moving element are often dissociated, this combination leads to visually interesting kinematics where the material itself deforms.

\subsection{A Buckling Actuator}

The second means of displacement amplification, illustrated in Fig. 4, relies on controlled buckling of elastic materials. We exploited the Euler buckling of two elastic steel ribbons with $1 \mathrm{~mm}$ thickness and $10 \mathrm{~mm}$ width, in a prototype similar to the one presented in [6]. Both ribbons contribute to realize the actuation movement and provide a spring-back force. 3D-printed hinges were manufactured in order to receive these steel ribbons as well as to crimp one central SMA wire $(0.5 \mathrm{~mm}$ diameter $)$. At ambient temperature (initial state), the steel ribbons are bent and the wire is thus pre-strained. Upon heating, the wire shortens and thus brings the ribbons to bend more. Upon cooling, the elastic strain energy contained in the ribbons provides the springback force to bring back the wire in its pre-strained state. 


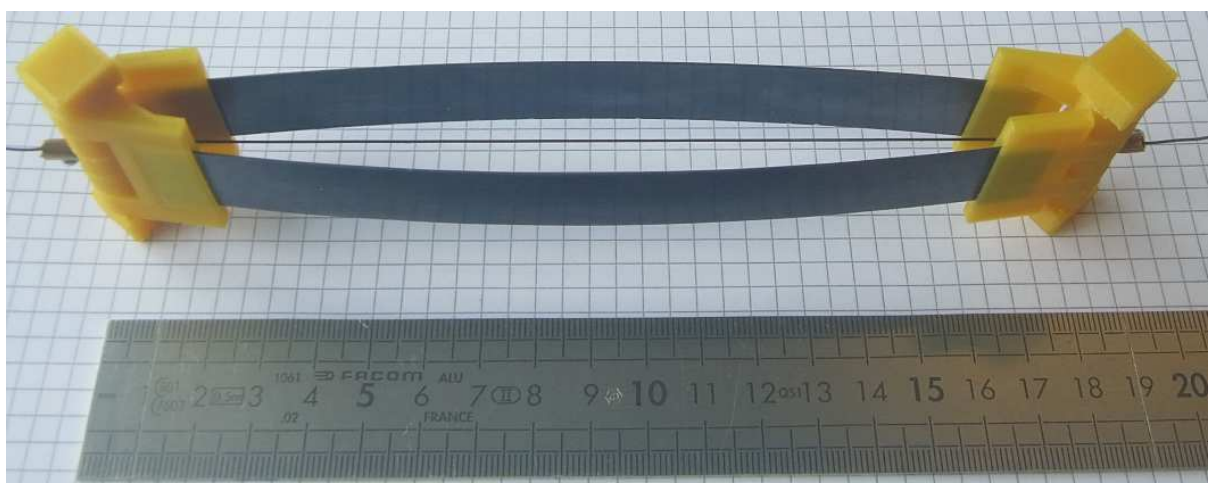

Fig. 4. Buckling actuator: initial state at ambient temperature

Actuation tests were also carried out on this prototype, with the same experimental method, starting at ambient temperature, with a heating phase followed by a cooling phase. In this experiment, the curvatures of the steel ribbons have been measured by DIC in order to determine the maximum distance between both ribbons, which we called the actuator's "opening”, highlighted in Fig. 5.

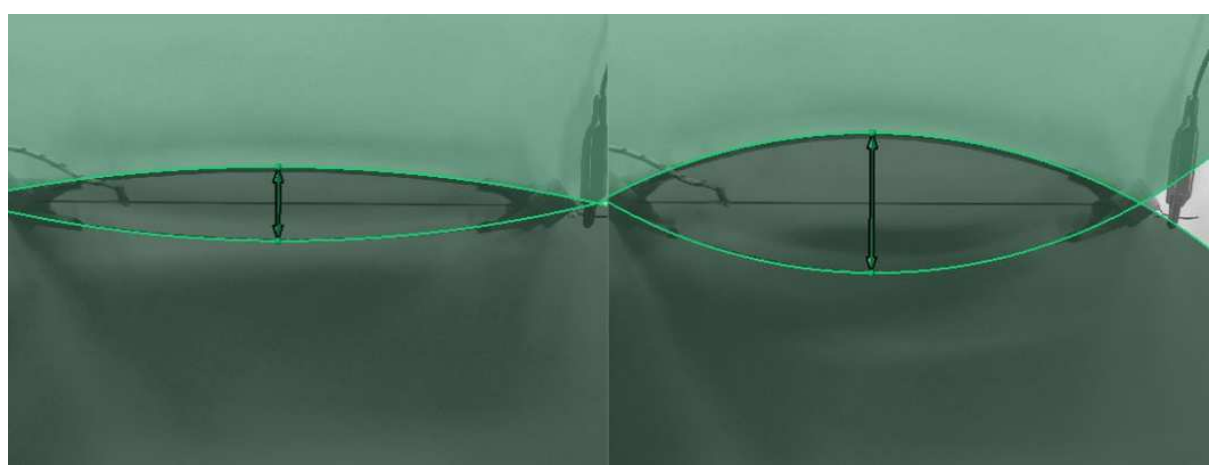

Fig. 5. Curvature and distance measurements for the buckling actuator: initial state at ambient temperature (left), actuated state with resistive heating (right). We define the actuator's "opening" as the length of the green arrow

The opening has thus been plotted with respect to the wire temperature in Fig. 6. In the same way as for the first prototype, the measurements highlight the actuator's hysteresis (See Sect. 1). We can identify a hot" and a "cold" state: above $64^{\circ} \mathrm{C}$ or below $23^{\circ} \mathrm{C}$, the actuator's geometry does not change. Between those two temperatures, the actuator's geometry depends on the loading history. The kinematic amplification described in Sect. 2 is illustrated here by the actuator's opening which increases by $19 \mathrm{~mm}$ during actuation while the SMA wire shrinks by approximately $4 \%$, which represents $7 \mathrm{~mm}$. This system had already been actuated many times before the experiment, and we can thus consider that the studied behavior is already stabilized. 


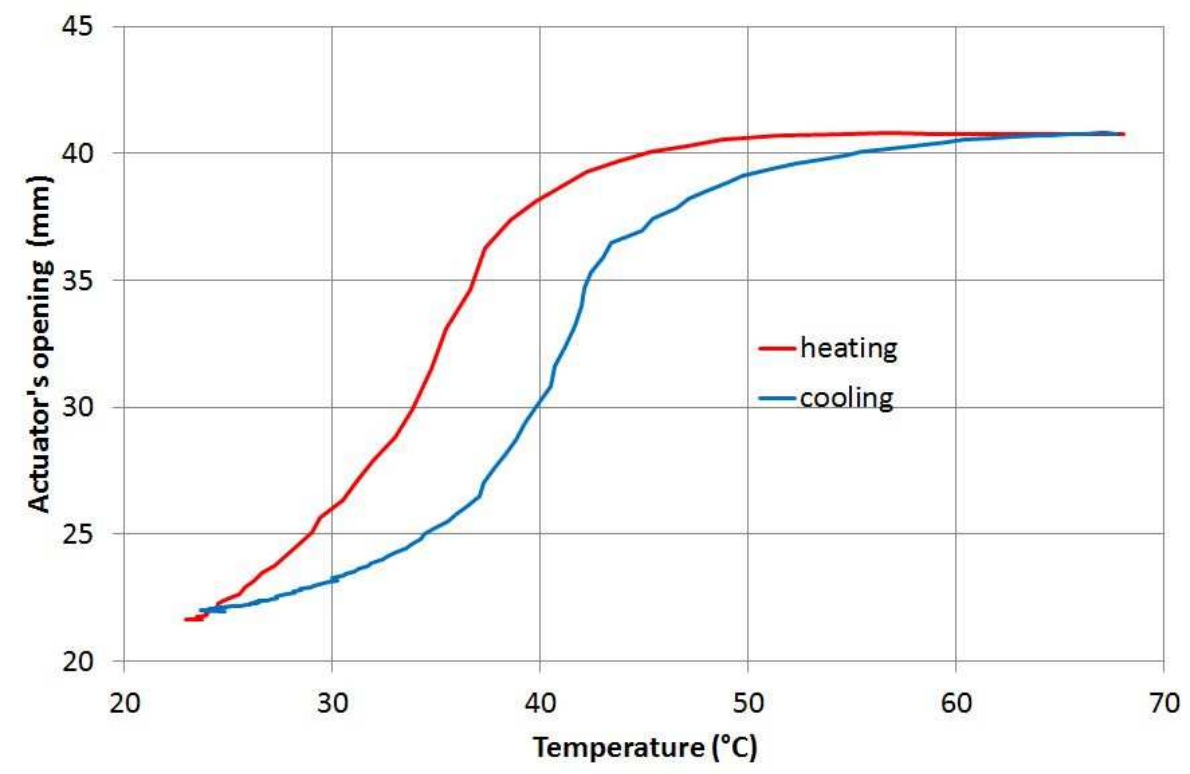

Fig. 6. Actuation test: Measurements of the actuator's opening length with respect to the wire temperature - Heating curve and cooling curve

\subsection{A Torsional Buckling Actuator}

Torsional movements have also been investigated, as shown in Fig. 7: a slender elastic steel ribbon undergoing rotations at its supports can produce a large displacement. The supports can freely rotate around their vertical axis, and one SMA wire is stretched between each side of the support: by heating one wire, the supports rotate in two opposite directions, inducing the torsional buckling movement of the elastic ribbon. In the specific material and geometric configuration of the manufactured prototype, the structure can remain in the deployed state without further actuation, due to gravity. Upon heating the other wire, the supports rotate back and the structure returns to its original position.

In this actuator, there is no springback force opposing to the movement of the actuators, except the elastic strain energy of the steel ribbon before it buckles. However, the two SMA wires can be actuated separately: the actuation of one wire enables the other wire to return to its pre-strained position. Thus, only one wire should be heated at one time. There is always at least one wire in a pre-strained and cold state. For this actuator, no measurements have been carried on yet. 


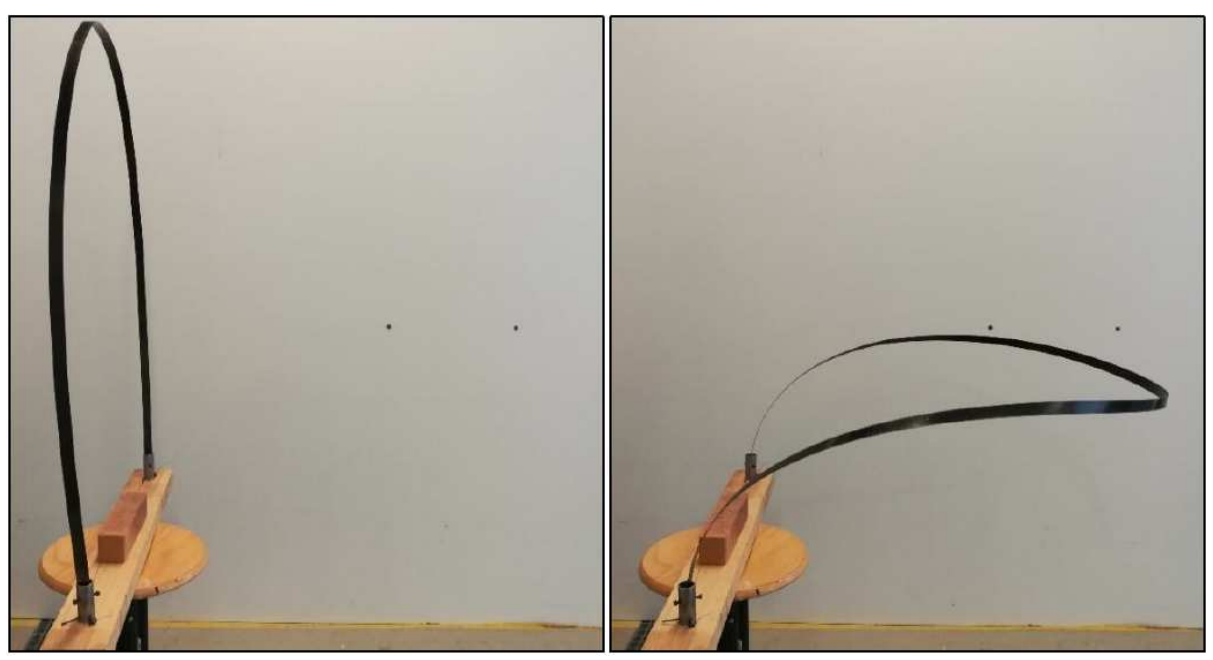

Fig. 7. Torsional buckling actuator: initial state (left) and deployed state upon actuation (right)

\section{$5 \quad$ Facade Integration}

The three presented prototypes could perform the structural function in sun shading devices, supporting a large and lightweight element, opaque or translucent (membrane, fabric or composite surface) performing the occultation. They could at the same time be the actuating parts of these sun shades. Exploiting the experimental data we can calculate the mechanical work supplied by the heated wires to the system constituted by the bent lamellae, through the following formula:

$$
W=\frac{1}{2} l . E I .\left(\chi_{f}^{2}-\chi_{i}^{2}\right)
$$

Where $\mathrm{E}$ is the elastic modulus of the lamella, $\mathrm{I}$ is its moment of inertia, 1 is its length and $\chi_{i}$ and $\chi_{f}$ are the initial and final curvatures of the lamellae. The results are presented in Table 1 .

\begin{tabular}{|c|c|c|c|c|c|}
\cline { 2 - 6 } \multicolumn{1}{c|}{} & $\mathrm{E}$ & $\mathrm{I}$ & $\chi_{i}$ & $\chi_{f}$ & $\mathrm{~W}$ \\
\hline $\begin{array}{c}\text { First Prototype } \\
\text { (Section 4.1) }\end{array}$ & $1,08 \mathrm{GPa}$ & $1,64 \mathrm{~mm}^{4}$ & $1,85 \mathrm{~m}^{-1}$ & $5,08 \mathrm{~m}^{-1}$ & $3,56 \cdot 10^{-3} \mathrm{~J}$ \\
\hline $\begin{array}{c}\text { Second Proto- } \\
\text { type (Section } \\
\text { 4.2) }\end{array}$ & $206 \mathrm{GPa}$ & $0,83 \mathrm{~mm}^{4}$ & $2,33 \mathrm{~m}^{-1}$ & $6,12 \mathrm{~m}^{-1}$ & $8,23 \cdot 10^{-1} \mathrm{~J}$ \\
\hline
\end{tabular}

Table 1. Comparison of the mechanical work supplied by the wire to the lamella for two prototypes

The difference of two orders of magnitude in mechanical work mainly stems from the difference in stiffnesses of the lamellae. Probably wood is not the right material for an 
upscaling of the first actuator. However, the calculation for the second prototype can give us interesting orders of height. The mechanical work supplied by the SMA wire with respect to its mass is:

$$
\epsilon=980 \mathrm{~J} / \mathrm{kg}
$$

The literature shows similar values for the specific energy of SMA actuators. This is why only a small quantity of SMA is needed in SMA actuators: a traction wire enables to fully exploit the potential of shape memory alloys. Even for an upscaling to a façade system, the quantity of SMA needed is expected to remain low.

Furthermore, the integration on the outer side of the façade needs the sun shades to be designed for high loads, such as wind loads and snow loads. This is why, at this step, an integration into a double-skin façade is planned, in order to avoid high design loads, to facilitate maintenance, as well as to increase service life.

Finally, the issue of the actuation temperatures inside a double skin façade needs to be addressed. Indeed, the air gap temperature can easily exceed $70^{\circ} \mathrm{C}$ on summer days. For an electric control, the actuation temperature will have to be superior to the air gap temperature.

\section{Conclusion}

This preliminary study aims at proposing some actuation principles for SMA-based sun protection devices. The three manufactured prototypes present the main characteristics of SMA actuators. First, they are stable below and above two temperature limits, but between these limits they are difficult to control, because imposing a temperature does not fully characterize the state of the device. Thus, SMA actuators are better suited for applications only requiring a change from one initial to a unique final shape. Secondly, the shape memory effect in SMAs only works in one way. In order to switch between two positions, an SMA actuator needs a springback force or different SMA wires actuating the structure in two different ways, at two different times. Finally, these 3 prototypes illustrate some advantages of SMA actuators over conventional actuators, like a silent actuation and a reduced number of mechanical elements.

We can also list some remaining technical challenges in SMA actuation. One drawback of this type of actuation is the lack of control upon the system: it is difficult to obtain a feedback on the real position of the actuator. Even upon electrical activation, measuring the resistivity of the wire is not a sufficient information to determine the state of the actuator: the wire's resistivity is variable and depends on the volume fractions of martensite and austenite phase. Furthermore, the energy consumption of these devices has to be studied and compared to other commonly used solutions. Indeed, SMA can provide a high energy output with a remarkably low weight, but resistive heating is a poorly efficient energy transfer. The continuous heating of SMA wires to maintain a deployed position can be questioned.

These three prototypes could be the basis elements of adaptive shading devices for building facades. Through this critical analysis of different actuation principles, the po- 
tential of shape memory alloys for architecture and façade engineering has been clarified. This work is being conducted in strong partnership with a façade consultancy firm. Material behavior research is being carried out in parallel with the design and analysis of different prototypes, aiming at realizing SMA actuators for sun shading devices.

\section{Acknowledgements}

This work has been partially funded by Arcora \& Ingérop Group and by ANRT under CIFRE grant No 2015/0495.

\section{References}

1. Basit, A., L'Hostis, G., Pac, M., Durand, B.: Thermally Activated Composite with TwoWay and Multi-Shape Memory Effects. Materials 6(9), 4031-45 (2013).

2. Charpentier, V., Hannequart, P., Adriaenssens, S., Baverel, O., Viglino, E., Eisenman, S.: Kinematic amplification strategies in plants and engineering. Smart Materials and Structures 26(6), (2017).

3. Fiorito, F., Sauchelli, M., Arroyo, D., Pesenti, M., Imperadori, M., Masera, G., Ranzi, G.: Shape Morphing Solar Shadings: A Review. Renewable and Sustainable Energy Reviews 55, 863-84 (2016).

4. Hannequart, P., Peigney, M., Caron, J-F.: A Micromechanical Model for Textured Polycrystalline Ni-Ti Wires. In: Conference Proceedings from the International Conference on Shape Memory and Superelastic Technologies (San Diego, CA, USA, May 15-19, 2017). ASM International, Materials Park, OH, USA (2017).

5. Mohd Jani, J., Leary, M., Subic, A., Gibson, M.: A Review of Shape Memory Alloy Research, Applications and Opportunities. Materials \& Design 56, 1078-1113 (2014).

6. Scirè Mammano, G., Dragoni, E.: Modelling, Simulation and Characterization of a Linear Shape Memory Actuator with Compliant Bow-like Architecture. Journal of Intelligent Material Systems and Structures 26(6), 718-29 (2015).

7. Thill, C., Etches, J., Bond, I., Potter, K., Weaver, P.: Morphing skins. The Aeronautical Journal 112(1129), 117-139 (2008).

8. Zhou, G., Lloyd, P.: Design, Manufacture and Evaluation of Bending Behaviour of Composite Beams Embedded with SMA Wires. Composites Science and Technology 69(13), 2034-41 (2009). 